\title{
A Review of Behavioral Strategies and Support Considerations for Assisting Persons with Difficulties Transitioning from Activity to Activity
}

\author{
Jay A. Sevin ${ }^{1}$ - Robert D. Rieske ${ }^{2}$ (D) - Johnny L. Matson ${ }^{2}$
}

Received: 2 July 2014 / Accepted: 15 July 2015 /Published online: 29 July 2015

(C) Springer Science+Business Media New York 2015

\begin{abstract}
Repetitive and restricted behaviors and interests are a major feature of Autism Spectrum Disorder (ASD). Insistence on sameness, rigid adherence to rituals and routines and resistance to change, and related symptoms can have a highly disruptive impact on an individual's ability to transition from one task to the next and progress through the different steps within a task. Difficulties with transitions can represent a major barrier in treatment and care, impede learning, and contribute to significant distress in individuals with an ASD. A number of behavioral approaches to facilitating transitions in persons with an ASD have been investigated. The current paper reviews the available research on strategies to support individuals in transitions between daily activities and tasks. Current trends and future directions are discussed.
\end{abstract}

Keywords ASD · Transition supports · Insistence on sameness $\cdot$ Repetitive and restricted behaviors and interests

Restricted, repetitive patterns of behavior which often manifest as insistence on sameness, inflexible adherence to

Highlights - Review of strategies available to assist in transitions between daily tasks in those with an Autism Spectrum Disorder (ASD)

- Strategies researched to assist individuals with ASD in better tolerating change and transitioning from activity to activity

- Discussion of current trends and future directions for research

Robert D. Rieske

rrieske@hotmail.com

1 Greater New Orleans Resource Center on Developmental Disabilities, Louisiana Office for Citizens with Developmental Disabilities, Alexandria, LA, USA

2 Department of Psychology, Louisiana State University, 236 Audubon Hall, Baton Rouge, LA 70803, USA routines, or ritualized patterns of behavior are among the defining features of Autism Spectrum Disorders (American Psychiatric Association (APA), 2013). Despite shifting emphases over the years with regard to diagnostic criteria, including evolving theories on the nature and diagnostic significance of specific social and communication deficits, "sameness" features have remained prominent in every conceptualization of autism dating back to the original seminal paper. Kanner (1943) described "repetitions carried out in exactly the same way," "verbal rituals recurring all day long," "insistence on sameness," satisfaction "unless someone made a persistent attempt to interfere with ... self-chosen activities," and "dread of change" in his original sample of children. Variations on these original observations have been described in individuals with autism for 70 years. In the DSM-V, insistence on sameness is included within the broader category of restricted, repetitive behavior. While there is no universally agreed upon definition of insistence on sameness, the term has perhaps most often been used to refer to adherence to rituals and routines and resistance to change which were highlighted in Rutter's definition of autism (Rutter 1971) and influential in formulating diagnostic criteria used in earlier versions of the Diagnostic and Statistical Manual (DSM). In discussing insistence on sameness, Rutter (1978) additionally referred to limited play patterns, intense object attachments, and unusual preoccupations.

Both the current and the previous version of the DSM (DSM-V, APA 2013; DSM-IV-TR, APA 2000) consider these to be core features of Autism Spectrum Disorders, despite other changes in criteria. The DSM-V (APA 2013) specifically lists "extreme distress at small changes" and "difficulties with transitions" as example criteria. Widely utilized autism screening and assessment scales invariably incorporate items and/or subscales related to the sameness domain of problems including resistance to change, repetitive behaviors, restricted 
interests, and/or difficulty with transitions (Lord et al. 1994, 2000; Matson et al. 2009c; Schopler et al. 2010).

Repetitive behaviors and sameness can present very differently in different people. The phenomenon is variable and complex and while most often discussed in the context of autism, these problems do appear in normal development (Evans et al. 1997) and in different psychiatric and developmental disorders (Green et al. 2006; Matson et al. 2009a; Prior and MacMillan 1973; Rojahn, et al. 2009). Some authors have referred to this inability to cope and adapt as behavioral inflexibility (Wahlberg and Jordan 2001). In one of the more conceptually thorough discussions of sameness features, Green et al. (2006), developed the Behavioral Flexibility Rating Scale to evaluate specific topographies of sameness issues in individuals. Items causing major distress in individuals with restricted or rigid routines were categorized as: item misplaced, event cancelled, activity interrupted, object moved, item unavailable, object breaks, sequence changed, unexpected interaction, event delayed, momentary separation, materials run out, annoying behavior, item put in wrong place, losing a game, and task left incomplete. While an exploratory factor analysis of items revealed all items loaded into a single factor, results from this study also highlight how idiosyncratic sameness behaviors can be across different individuals. The authors proposed there may be value, from the standpoint of treatment planning, in identifying the specific situations associated with an insistence on sameness that cause distress in individuals.

In the past few decades, there has been a welcomed increase in research on treatment for persons with ASD. Early intensive behavioral therapy in young children with autism, in particular, has become one of the most intensively studied interventions in child clinical psychology today. While most reviews of the literature acknowledge the need for more research, as well as noting methodological shortcomings in some studies, the congregate literature of learning based methods presents a compelling agreement for treatment gains in most children (Matson and Minshawi 2006; Matson and Smith 2008). There is a growing body of literature describing behavioral treatment approaches which have resulted in substantial gains in core social and language components of autism (Cohen et al. 2006; Eikseth 2009; Goldstein 2002; Howard et al. 2005; Jones et al. 2006; Koegel et al. 2001; Matson et al. 2009b; Sherer and Schreibman 2005; Stahmer 1995). In comparison to studies on improving communication and social skills, directly contending with and addressing repetitive behaviors, sameness, and transition issues has perhaps received less attention in the literature (Matson and NebelSchwalm 2006) despite the fact that this feature of autism can be among the most disruptive to family life and most debilitating for the individual (Reese et al. 2003).

Kanner (1943) descriptions noted that these children "stick to the same thing" and parents often refer to the overwhelming repetitive aspects of autism as their children getting "stuck," whether this manifests as repetitive motor behavior, perseverative speech, restricted interests, unusual preoccupations, rigid adherence to routines, or difficulty with progression from activity to activity. The disruptive and debilitating impact these behaviors can have on individuals, their lives, and families is unequivocal. Howlin and Rutter (1987) described the frustrations of parents who have to contend on a daily basis with children's rigid routines and preoccupations - how even activities that a child enjoys can be ruined by minor changes or difficulties transitioning into the activity. Mialaret (1996), writing from a parent's perspective, talked about his family's personal struggles with his child's sameness issues-the "legions of rituals" and "straight jacket of sameness" that dominate family life. Teachers often report the challenges associated with moving from one instructional activity to another (Banda et al. 2009); simple attempts to help the person to navigate through the activities of the day can disrupt other students and may constitute some of the most difficult aspects of working with persons with autism. Problems with change and transition can negatively impact learning (Koegel and Covert 1972). Difficulties with changes in tasks, routines, or environment can manifest as verbal outbursts, aggression, self-injury, and/or simple refusal to transition which disrupt teaching sessions as well as interfering with the ability to participate in community settings (Schreibman et al. 2000). More importantly, failure to incorporate transition supports can contribute to significant, and perhaps avoidable, distress in persons being served. After such distress, refocusing someone to learn or even enjoy the day can be difficult. Valuable instructional time is lost, and the entire process can take a stressful and draining toll on the individual and caregivers.

As a result, some researchers have suggested assisting individuals by directly addressing their problems with sameness and purposefully building in supports to encourage less restricted responding and smoother transitions. The following manuscript attempts to review some of the strategies that have been discussed and evaluated in the literature to assist individuals in better tolerating changes in tasks and more easily and pleasantly transitioning from activity to activity. While the current paper primarily reviews empirical studies relevant to supporting transitions, some potentially promising strategies with less empirical support are also discussed in the interest of encouraging future research. The aim is to present the reader with a menu of options to consider in constructing transition supports.

\section{Review of Strategies to Support Transitions}

\section{Altering Timing of Requests}

Some individuals have greater difficulty in transitioning from one task to another if the transition is requested at a time when 
they: (a) are currently engaged in a highly preferred activity or (b) have not been given the opportunity to complete the current task. This trend may be apparent during simple observations or in the context of conducting a functional assessment. For some individuals, timing the transition, if circumstances allow, so that it does not occur during one of these events may result in an easier transition and less distress for the person.

Fritz et al. (2004) studied two individuals who engaged in destructive behavior when demands were presented. Initial data from functional assessment could be interpreted to suggest that behaviors were maintained by negative reinforcement, an attempt to resist and escape from demands. However, subsequent analyses revealed specifically that challenging behaviors persisted when participants were asked to terminate a highly preferred ongoing activity. The authors concluded that the request to engage in a new task itself was not the critical variable except in relation to the termination of the preferred activity.

Miltenberger (2006) suggested that by altering the timing of requests to correspond to the completion of a preferred or reinforcing activity, an individual may be less likely to engage in problem behavior maintained by escape from having to change activities. For example, a request when a favorite television show is finished may be less likely to result in problem behaviors than a transition that is attempted in the midst of the activity. Scheduling activities so that highly preferred tasks, embedded within the schedule, have naturally occurring end points which limit the duration of that task may complement this approach .

\section{Advance Notice—Allowing Extra Time after Signaling Upcoming Transition to a New Activity}

In actual clinical and classroom practice, one transition support strategy that is widely utilized involves giving an individual advance notice of an upcoming change. Signaling change and allowing extra time before the transition occurs can sometimes have a beneficial impact on transitioning. For example, Tustin (1995), using an A-B-A-B design, studied the impact of requesting techniques on the stereotypical behavior, body rocking and hand flapping, of a man with autism and a moderate intellectual disability. The two variations for requesting a change in activities included one technique that involved advance notice while the other required immediate change. In the immediate change condition, the investigator asked the participant to change tasks, substituted new work materials for current ones, and praised cooperation. In the advance notice condition, the investigator asked him to change tasks, placed new work materials, but then walked away with current work materials still there, allowing the participant $2 \mathrm{~min}$ to transition to the new activity; cooperation was praised. Stereotypies occurred at much higher rates in the immediate change condition, with most stereotypical behavior occurring within $10 \mathrm{~min}$ after requests to change tasks. The individual changed tasks $60 \%$ of the time in the immediate change condition and $90 \%$ of the time with advance notice. In this study, the advance notice was in the form of a visual cueplacement of new work materials.

Flannery and Horner (1994) studied teenage students who displayed severe problem behaviors including aggression or self-injury when novel or unsignaled events occurred. Unsignaled variability in tasks was incorporated into the functional assessment. Unsignaled variability contributed to transition difficulties and elicited escape-motivated problem behaviors. In the first of two single-participant studies, an A-BA-B design was employed. In baseline phase (A), problem behaviors increased when previously unknown tasks were introduced. In the predictability phase (B), the investigators described and modeled steps involved in upcoming tasks, including both familiar and unfamiliar activities. Providing advance notice of the tasks and steps involved was accompanied by dramatic decreases in problem behaviors. In the second study, an $\mathrm{A}-\mathrm{B}-\mathrm{C}-\mathrm{B}-\mathrm{C}$ design included: A (Constant Schedule) - consistent routine with regard to sequence and duration of tasks which resulted in low rates of aggression and property destruction; B (Random) - both sequence and duration of tasks were altered resulting in high rates of problem behaviors; C (Random + Predictable) - sequence and duration of tasks varied but the participant was provided in advance with printed sequence of tasks, a timer, and advance notice of the specified duration of tasks, resulting in low rates of problem behaviors comparable to A phase. The authors operationalized "predictability" as the presentation of signals that indicate the availability of specific $\mathrm{S}>\mathrm{R}>\mathrm{S}$ relationships and posited that these signals may serve as establishing operations that alter the likelihood of problem behaviors. They concluded that the environment did not need to be consistent but it did need to be predictable to decrease challenging behaviors for these individuals.

\section{Visual Schedules}

Perhaps the most studied category of interventions to facilitate transitions in persons who have difficulty with change involves the incorporation of visual activity schedules into the daily routine. Activity schedules typically are visual support systems that display drawings, images, or photographs in the sequence that corresponds to the person's routine for some period of time. Visual schedules have been touted both in terms of their adding to the predictability of the person's day as well as capitalizing on the visual-learning strengths present in some persons with ASD (Hodgson 1995; Schopler et al. 1995).

The works of McClannahan and Krantz (1999) are often cited as contributing to the use of visual schedules for persons with autism and demonstration of their efficacy in facilitating schedule-following. For example, MacDuff et al. (1993) used 
graduated guidance and photographic activity schedules to increase on-task behavior and schedule-following in four children, aged 9-14, with autism and severe language delays. Participants' behavior problems included aggression, tantrums, running away, and stereotypies. The study utilized a multiple-baseline across participants design. Dependent variables included percent of time on-task (visual orientation toward and/or manipulation of task materials) and percent of time on-schedule (child was engaged in activity on displayed photo when observed). Treatment was delivered in a community home setting. A photographic activity schedule, including six leisure and homework tasks, was developed for each child displayed in a three-ring binder. Treatment included the teacher using manual prompts to guide the child to open the binder and then work in sequence through the tasks as ordered in the binder. Manual prompts were delivered from behind the child, then faded to shadowing without touch, and then faded altogether in the maintenance phase of the study, with children demonstrating the ability to transition independently between six tasks. Verbal prompts were not used so that schedule following would come under stimulus control of the visual schedule and was never dependent on teacher verbal prompts. On-task and on-schedule behavior rapidly increased with the addition of the visual schedule. Use of manual prompts dropped to low levels for all four children by the 6th session. Schedule-following generalized in a condition in which tasks were re-ordered from the original sequence, showing they were transitioning according to the altered visual schedule and not simply following a consistent previous schedule. Benefits of this approach as listed by the authors included that learners displayed the ability to follow schedules in the absence of teacher prompts and that children acquired lengthy response chains of moving through the sequence of activities.

Bryan and Gast (2000) conducted a partial replication of MacDuff et al. (1993) using similar graduated guidance and visual schedule strategies. The study differed in that the four participants, who had autism, were slightly younger (ages 78), had less significant cognitive disabilities, received treatment in a classroom setting (with focus on literacy-based skills), and used schedules that utilized line drawings instead of photographs. An A-B-A-B design was employed with the activity book being utilized in the $\mathrm{B}$ phase and withdrawn in the second A phase. On-task and on-schedule performance improved to $100 \%$ using the treatment strategies in both (B) treatment phases and an ability to fade manual prompts was demonstrated similar to the MacDuff et al. (1993) study. Both of these studies outlined methodologies for teaching children with autism to transition between activities independently. Participants in the MacDuff et al. (1993) study were noted to have significant behavior problems although it was not noted that problems occurred specifically in response to transitions.

Dettmer et al. (2000) studied the impact of visual schedules on time spent transitioning from one activity to another in two children (ages 7 and 5) with autism who exhibited problems with changing from one activity to another. Single-participant $\mathrm{A}-\mathrm{B}-\mathrm{A}-\mathrm{B}$ designs were employed. During Baseline (A phases), verbal prompts (e.g., "time for pizza," "time for work"), physical prompts, and proximity control were employed. A verbal prompt was given. After one minute following the verbal cue, if transition to the next activity did not occur, children were cued again and then again at 1-min intervals up to $10 \mathrm{~min}$, after which physical prompts were employed. For B phases, visual schedules were employed for community activities for the 7-year-old in the form of a long foam strip with line drawing pictures added, depicting the series of planned activities for the day, attached to the dashboard of the car. A portable photo book with an identical series of line drawings was also used. The visual schedule was reviewed with the child prior to getting in the car and then periodically reviewed (pointing to picture paired with verbal cues) as activities progressed; "finished" was said at completion of a task and as new activities were about to begin. Average duration between the verbal cue to transition and actual transition averaged over $6 \mathrm{~min}$ in the two baseline phases, and dropped to 1.8 and $1.6 \mathrm{~min}$ in the two treatment conditions, respectively. Use of physical prompts dropped to zero by the second treatment phase. With the second child, visual schedules were employed in a home-based educational program teaching pre-academic skills. Again the visual schedule included line drawings. The schedule was reviewed with the child prior to initiating work, with the instructor talking out each item on the schedule. Work was written on index cards and as each task was completed, the boy was allowed to deposit the card in a "finished" box. Break time in between major tasks was limited using a color coded timer; when "red" on the timer was gone this was the cue to return from a preferred fun activity to work. Latency between cue to transition and actual transition decreased from over two minutes in both baseline phases to under $1 \mathrm{~min}$ in both treatment phases. For both children, the use of verbal prompts also decreased during treatment. The children also frequently self-initiated looking at the schedules and showed approach behavior and positive vocalizations to the visual schedules. The authors reported one child tried to get the experimenter to re-introduce the visual materials during the second baseline phase.

Dooley et al. (2001) demonstrated the positive effects of a schedule board based on the Picture Exchange Communication System (PECS). The participant in their study was a 3-year-old with a Pervasive Developmental Disorder. Functional assessment yielded data indicating that tantrum behavior, including hitting, kicking, and biting, primarily occurred when transitions between activities were initiated. Parents also noted difficulty with changes in routines at home. Both escape from switching activities and teacher attention were hypothesized to be maintaining consequences. 
Treatment included a PECS-based schedule board consisting of line drawings of daily activities and settings. The student and his teacher reviewed the board and schedule together at the beginning of the day, then he removed the first picture and was led to the first activity, where a matching picture was waiting. Upon activity completion, the picture was deposited in a container and he received a small edible. Following consumption, he returned to the schedule and similarly resumed the next task. There was a greater than $50 \%$ reduction, compared to baseline rates (in A phase), in tantrum behaviors at transition times immediately following the introduction of the visual schedule (in B phase) and an increase in cooperation, defined as a quiet response to classroom transition cues by stopping one activity and following teacher directions to the next. After three days of schedule use, behavior problems at transitions fell to zero. A "C" phase of the study included discontinuation of edible reinforcers, which did not impact behavioral gains. Anecdotally, parents introduced the visual schedule at home and reported decreased tantrums during household transitions including when daily home routines were changed on weekends and holidays.

Banda et al. (2009) summarized helpful steps for the construction of visual schedules to assist students in transitioning between assignments and environments (Table 1). Steps included:
One variation of the visual schedule has been researched and discussed by Mechling and Savidge (2010) in which a personal digital assistant (PDA) is used to provide visual prompting for transitions between different tasks and within different components of the same task. The study involved the use of the PDA which had different levels of prompting (picture, picture + auditory, and video) examining their effectiveness in task completion and transition in three middle school students. The researchers found that two of the three students completed more tasks using the PDA when compared to a picture-based task strip but did not have any significant differences in performance on within task transitions; however, in terms of transitions between tasks they found that all three students successfully completed more transitions when compared to use of the task strip. While further research is needed to investigate the use and effects of PDA's and other digital devices, as well as the use of video prompting, recent studies show promise in the use of PDA's to increase more independent transitioning between tasks (Gentry et al. 2012; Palmen et al. 2012).

Additional reviews of the efficacy of visual schedules can be found in Banda and Grimmett (2008), Koyama and Wang (2011), and Lequia et al. (2012). Despite some non-overlap in these papers regarding studies reviewed, population focus (ASD vs. broader range of developmental disabilities), and

Table 1 Steps for constructing visual schedules (Banda et al. 2009)

Steps for constructing visual schedules

1. Identify and define target transition behaviors

2. Collect baseline data on problem behavior

3. Choose a between-activity or within-activity schedule

4. Choose a mode of presentation

5. Choose a medium

6. Choose a location for the schedule

7. Train the student to use the activity schedule

8. Collect intervention data

9. Add new pictures or words

10. Fade prompts

11. Fade the prominence of the schedule

12. Promote generalization
Identify difficult transition times or activities. Are there specific situations that are difficult? Are there problems with terminating an ongoing activity? Starting a new activity?

Collect data on frequency or duration of challenging behaviors prior to initiation of treatment

Will the visual schedule address transitioning across different activities (e.g., daily schedule) or across different steps within a task or activity (e.g., task-analyzed steps)?

Different modes are possible including notebooks, binders, or long cardboard or foam strips with Velcro-ed images. Electronic representations on tablet devices, for example, are another option.

Photographs, line drawings, and computer-generated images have all been employed in different systems.

Display the schedule in a location that is familiar to and useful to the individual. In some cases portable systems may be utilized.

This typically involves one-on-one instructor time with frequent referencing of the schedule, pairing the schedule and activities, and teacher prompts which are faded as the person becomes familiar with using the schedule.

This may include adaptive data such as on-task behavior and independently completing tasks and transitioning as well as data on problem behaviors.

After initial mastery, extend the schedule to longer periods of time or new tasks.

Prompting should be reduced as familiarity with the system increases and the child demonstrates independent behaviors.

Make efforts to make the schedule less obtrusive and more socially and age appropriate.

Generalization across activities and settings are options. 
principle focus of the review, collectively the reviews suggest very good evidence for the efficacy of visual schedules across different targets including self-regulation of challenging behaviors, independence, play, or transitions. Lequia et al. (2012) did not find differences in efficacy of visual schedules as a function of the target of the study (e.g., ease transition and improve play engagement), severity of ASD of participants, communication abilities of participants, or modality of visual schedules (photo, line, or video formats).

\section{Priming Strategies}

Some authors have explored "priming" as a way of supporting transitions. In priming, the individual is exposed to aspects of a future event or steps of a future activity prior to requiring actual participation or demonstration. In some cases the priming may occur in a different setting. In some cases, priming can take the form of "dry run" pre-activity rehearsal in the actual setting in which the activity will later occur.

Sevin et al. (2001) used a priming procedure to assist a young woman with an ASD who cooperated with caregiver prompts to go through the steps of hygiene activities but would get stuck at each step and wait for caregivers to verbally prompt her through each and every step of the task. She could not transition from step to step without a specific verbal prompt. A task-analyzed list of the steps for three morning hygiene tasks was prepared. Priming included that prior to executing a task: (1) she read the list, (2) steps were reviewed with her, and (3) she practiced the motions of moving from step to step through the hygiene task. She was then allowed to bring with her and read the list during actual execution of the hygiene task. A multiple baseline across behaviors (hygiene tasks) design was employed and the dependent measure included the percentage of steps in hygiene tasks performed without caregiver prompts. With the sequential introduction of the priming strategy and written instructions, she reached $100 \%$ performance without caregiver prompts on each activity. Access to lists was then faded, first during performance of the activities and later prior to the tasks without loss of performance.

Schreibman et al. (2000) reviewed studies on the use of priming to teach new skills, discussed the strong visual learning abilities of some persons with autism, and developed a video priming procedure (shot from the point of view of the child, showing what the child would see) which was applied to helping children who displayed disruptive behavior problems in transition situations during daily routines and community settings. Participants included three children who displayed tantrums, including verbal resistance and aggression, at least $50 \%$ of the time during specific targeted transition situations. Problem behaviors resulted in family hardship and sometimes injury. For one child, the video priming intervention included having him view a video of his "going" routine, including going to the bathroom, washing his face, putting on shoes, and getting into the car. For the second child who displayed tantrum behavior at the mall when his parents attempted to take him anywhere but his favorite store, video priming included having him watch videos that began at different entrances of the mall, went through several stores, and ended at his favorite store. For the third child, who also had difficulty in the local Target store, video priming included having him watch a route through the Target stopping at various departments before going to the toy section and checking out. Children were exposed to their videos immediately prior to going into the transition situation and either received praise or access to a toy for watching the video. Video priming was evaluated using a multiple-baseline across participant design. All three children demonstrated significant decreases in tantrum behavior during the treatment phase of the study. Positive response to treatment was rapid for some cases and circumstances and required multiple exposure to the videos for other cases and circumstances, but resulted in positive outcomes for all participants which maintained at one-month follow-up. The study is noteworthy not only for the application of priming techniques to transition difficulties but also for its use of a visual medium using individualized, relevant, naturalistic footage as a means of increasing predictability of future events and supporting transitions. The authors cited Zanolli et al. (1996) who recommended that: (1) priming sessions should be completed prior to the actual event, (2) there should be low demands during the priming session, and (3) the priming session should have potential sources of reinforcement.

\section{Modeling}

Modeling is often incorporated into instructional strategies and has been used as a principle or component strategy to teach a host of skills to persons with developmental disabilities. Stahmer (1995) used modeling, child toy selection, and positive reinforcement to teach symbolic play to children with autism and to reduce restricted, stereotyped play. Variations of adult, peer, or self-modeling have been used to teach social initiations, social skills, and many aspects of language functioning (Buggey 2005; Fredeen and Koegel 2006; Huang and Wheeler 2006; Koegel and Koegel 2006). Modeling is employed as a component in many treatments for challenging behaviors. By increasing skills, restricted behaviors and perseverations are often impacted. The use of modeling approaches to assist with transitions has been explored in a few studies and may represent a promising area for future research.

In a recent study, the effectiveness of self-operated video models in teaching novel tasks and independent transitions between tasks was examined using a multiple-baseline design across settings (Taber-Doughtry et al. 2013). The study 
included four adolescents with a moderate intellectual disability and used an Apple iPad as the delivery method of sixteen video clips with audio instructions. The video models, graduate students, demonstrated novel tasks with step-by-step instructions in several different settings (i.e., school workroom, grocery store, or bowling alley). All participants had decreases in transition durations and increases in successful task transitions and performance.

Buggey (2005) has written extensively on applications of video self-monitoring to teach a host of skills to persons with autism. In video self-monitoring, video footage is shot of the individual, the videos are edited to show a desired version of the target skills, and the individual is allowed to view him/ herself exhibiting the desired behavior. Buggey (2005) describes two procedures for securing video footage of the person engaging in the desired behavior: (1) the person is taped over time until the desired behavior is displayed or (2) the person is assisted to role play or imitate the desired behavior and this is recorded. The first approach is more timeconsuming but may be necessary if the individual has difficulty imitating others or will not cooperate with a role play. Buggey (2005) allowed students who displayed aggression or other challenging behaviors to watch videos of themselves refraining from displaying problem behaviors in situations where problems typically occurred. Participants were students with ASDs aged 5 to 11. A series of multiple baseline studies are included in the paper. Some of the problems related to insistence on sameness displayed by participants included perseveration on tasks, perseverations in speech, and fairly continuous preoccupation with a science fiction TV show. Insistence on sameness issues with two of the participants also involved displays of disruptive behavior when frustrated due to expectations not being met or transitioning through some activities when expected aspects of class routines did not occur. Duration of time engaged in tantrums decreased by approximately $90 \%$ for both of these students following implementation of video self-monitoring in which they watched themselves handle changes or unexpected outcomes without tantrums. Video self-monitoring was also used to teach social initiation and interaction skills and language skills in some of the participants.

Cihak (2011), using an alternating treatment design, compared relative benefits of static picture vs. video self-modeling to assist four students with ASDs and mild to moderate adaptive skills deficits, aged 11-13, with transitioning across school day tasks. Challenging behaviors displayed by the children ranged from aggression to loud vocalizations to simple refusal/dropping to the floor. With static picture schedule phases, students were shown five pictures of themselves successfully transitioning across school activities (e.g., reading to computer and recess to math). In the video modeling schedule condition, students were shown five video clips of themselves successfully transitioning. The design included counterbalancing of pairings of tasks with modality across students to avoid confounds. All four students benefitted from both procedures, with the dependent variable being percentage of independent transitions. The author reported two students reached criteria faster using the video schedule, one student using the static picture schedule, and one student performed similarly using both schedules.

\section{Behavioral Momentum}

A promising strategy applied to supporting transitions from activity to activity involves the use of Behavioral Momentum approaches. Mace et al. (1988) describe behavioral momentum strategies as the issuing of a sequence of commands with which the participant is very likely to comply (highprobability commands) immediately prior to issuing a lowprobability command. When effective, the high-probability command sequences result in a "momentum" of compliant responding that persists when low probability requests are issued. Mace's early work was influenced by Nevin et al. (1983) who conceptualized behavioral momentum as analogous to mass and velocity in physics; Mace et al. (1988) suggest that by issuing high-probability commands which are reinforced, this indirectly manipulates the rate of reinforcement of cooperative responses to establish what appears to be "momentum." The physics analogy is perhaps attractive in conceptualizing attempts to help individuals become "unstuck" from the gravity of repetitive, restrictive preoccupations and behaviors which prevent transitions.

Mace et al. (1988) in a series of five single-participant studies employing reversal conditions used behavioral momentum interventions to improve cooperation with requests in adult men with moderate to severe intellectual disabilities and noncompliant behavior with simple requests. Challenging behaviors in participants included aggression, property destruction, and stereotypies. Participants displayed increased cooperation and decreases in latency from initiation of request to compliance. One participant who took excessively long showers (averaged about $90 \mathrm{~min}$ in baseline) and who would essentially become stuck in this activity was able to eliminate about an hour a day from his showering routine.

Mace and Belfiore (1990) employed behavioral momentum strategies (issuance of a series of high-probability instructions such as "Give me five." or "Hold my hand." prior to low-probability requests ) with a 38-year-old woman with a severe intellectual disability and high frequency repetitive, stereotypic touching of objects and people that interfered with performance of household tasks. The authors also incorporated extinction approaches, minimizing social attention and escape from demands. The design included a multiple schedule design with two experimenters, with experimenter 1 utilizing behavioral momentum strategies and experimenter 2 not using the strategy (experimenter-condition pairings were reversed 
across phases of the study). With intervention, cooperation improved and ritualistic touching was reduced by two thirds.

Ardoin et al. (1999) applied high-probability instruction sequences in a classroom setting to increase student compliance with transitions from one instructional activity to another. Participants were three children 7-8 years old who had difficulty transitioning from one morning routine to another. Introduction of high-probability instructions prior to requests to transition (low probability instruction) resulted in increased compliance with the request to transition and decreased response latency. The number of high-probability requests preceding low probability requests were faded from three to one and then eliminated over the course of the study.

\section{Use of A Transfer Stimulus + Competing Alternate Reinforcer (Vs. Alternate Reinforcement Alone as a Function of Stereotypies)}

Koegel et al. (2006a) proposed alternative approaches to facilitate transitions if stereotypies are occurring vs. not occurring. The authors posit that stereotypic behavior occupies a particularly high place in the child's reinforcement hierarchy. Therefore, if stereotypic behavior is occurring prior to a request to transition, simple attempts at presenting alternative reinforcement may be unsuccessful - transition may be facilitated by: (1) presenting a transfer stimulus which serves to interrupt stereotypic behavior, interrupt the reinforcing properties of the stereotypy, and divert attention to a new stimulus and (2) presenting a competing alternative reinforcer. Examples of transfer stimuli might include counting to 5, singing a favorite song, swinging the child, or doing something else that captures the attention of the child. Presenting a competing reinforcer might include saying, "We are going to swing 5 times and then we are going for a ride." The approach attempts to prompt orientation to external stimuli, reduce the strength of the ritualistic object or activity by interrupting it with the transfer stimulus, and then bring to bear individualized powerful alternate reinforcers to compete with the stereotypy. When a stereotypy is not occurring, the authors suggest more immediately presenting the alternate reinforcer and proceeding (e.g., "We are going for a ride."). The authors presented a single-participant case study with a young child with intense preoccupations who benefited from this approach. Orientation to other stimuli did not occur with simple introduction of alternative reinforcement during stereotypies, improved with presentation of the transfer stimulus during stereotypies, and if stereotypies were not occurring improved with alternate reinforcement without transfer stimuli.

\section{TEACCH}

This review focuses primarily on component transition support strategies which have been investigated in behavioral research. The comprehensive treatment model Treatment and Education of Autistic and related Communication handicapped CHildren (TEACCH) is addressed in this section given the special emphasis of TEACCH on developing education systems that facilitate transitions across tasks. TEACCH began in the 1960s through the Department of Psychiatry of the University of North Carolina School of Medicine and has become one of the more internationally well-known comprehensive treatment models for persons with autism. TEACCH services are guided by several principles articulated in Schopler $(1989,1994)$. Of particular interest in this review are emphases on: (1) improvement of the ability of the person with ASD to adapt to their environment through skills training and environmental modifications to accommodate deficits and (2) employing a tightly structured environment. Programs based on TEACCH systems typically employ visual schedules; physical organization of the environment with place-activity correspondence; task organization where visual materials are arranged to provide clear instructions to the person to promote greater independent functioning; and behavioral work routines where the person takes, completes, and returns, often in a left to right sequence, task materials and then transitions to the next task sequence. Once the person learns this chain of responses, teacher prompts are faded and the chain can be generalized to new activities and settings. These systems are designed with an aim to build in supports to counter deficits often found in persons with autism including difficulty moving through activities (too quickly or slowly or having problems identifying an activity's beginning or end or duration) and transition difficulties due to attachment to routines (Mesibov and Shea 2010). When effective, TEACCH students demonstrate an ability to work and transition across tasks independently, often for extended periods of time (Mesibov et al. 2005).

Despite widespread use not only in the USA but in replication projects in other countries including Italy (Panerai et al. 2002) and Germany (Probst and Glen 2011), previous reviews of treatment models have often noted a paucity of evaluative empirical studies of TEACCH as well as some methodological shortcomings in early research (Matson and Minshawi 2006; Odom et al. 2010). However, the number of studies of TEACCH has grown in recent years. Relevant to this review, Probst et al. (2010) described a series of studies including a single-participant study with a 7-year-old girl with autism and a severe intellectual disability who displayed restricted and stereotyped solitary activities and aggression. Standard TEACCH approaches were employed including teaching behavioral chains of progressing through and across tasks. The authors reported more autonomous handling of her schedule, more independent transitions through tasks, and decreases in problem behaviors. Probst and Leppert (2008) studied 10 children with autism; children had a mean age of 10. The authors employed spatial and temporal structuring of 
the school and social environment, structured design of tasks, and visual communication aids in a TEACCH framework. Statistical analyses revealed medium pre-post effect sizes on transition-related and sameness targets including "is not able to work independently on his or her individual work tasks" and "has little motivation to find out or do something new." Researchers have evaluated the effects of a comprehensive home-based early intervention TEACCH program for twenty 2-3-year-old children with autism (Welterlin et al. 2012). The study employed a series of multiple-baselines across pairs of participants. Most pairs showed clear increases in independent functioning which included progressing through and across tasks. Additional group outcome studies with controls have reported benefits of TEACCH for children with autism across multiple language, adaptive behavior, and educational skill domains including TEACCH delivered in a residential setting (Panerai et al. 2002), implemented in a natural home and mainstream school setting and evaluated over a three year period (Panerai et al. 2009), and in a longitudinal study with pre-schoolers using a low intensity (school plus one hour of parent intervention) model (D'Elia et al. 2014). Several studies also reported reductions in caregiver stress with implementation of TEACCH (e.g., Probst and Glen 2011; Probst and Leppert 2008).

\section{Discussion}

Repetitive, restrictive patterns of behavior and difficulty with change/transitions are core features of autism spectrum disorders and occur in some persons with other disabilities. These problems can contribute to severe distress in the person and can be debilitating in how they impact the person's ability to interact with others and the environment and move through daily routines. A number of researchers have studied the impact of specific behavior support approaches on facilitating daily transitions.

Strategies reviewed in this paper included altering the timing of requests, advance notice, visual schedules, priming strategies, modeling, behavioral momentum approaches, use of transfer stimuli, and TEACCH. Summaries were presented with an aim toward providing clinicians with some options to consider in structuring treatment for problems related to cooperating with transitions across activities. The authors also recommend the following review papers that have each highlighted unique emphases relative to transition support considerations including Lequia et al. (2012) and Koyama and Wang (2011) [reviewing research on activity schedules]; Sterling-Turner and Jordan (2007) [with special focus on applications for classroom and student supports]; and Boyd et al. (2012) [which addressed intervention strategies with differentiation between "lower" and "higher" order repetitive behaviors]. The body of literature taken together does suggest there are a number of treatment options that can be used to directly target difficulty with transitions. The studies summarized in this review included participants with and without ASDs, included youths and adults, were carried out in different settings (e.g., home settings, communities, schools, community homes, and work settings), and describe procedures that were implemented by different persons (e.g., teachers, parents, and researchers).

While studies cited above were grouped according to the principal focus of the paper as highlighted by the authors, it should be noted that most interventions described above incorporate multiple strategies and sometimes cut across categories. While several authors have reported increased task performance, increased flexibility in changing tasks or altering rituals, and decreases in disruptive behaviors accompanying transitions, the precise mechanisms responsible for improvement are not well understood. For example, while Tustin (1995) study focused on advance notice and delay, the author pointed out that by allowing up to a 2min delay following the signal of change, individuals were sometimes able to complete a task or quit at a breaking point. Therefore, altered timing elements may also have come into play. He also noted that individuals often stopped and looked at their work prior to switching tasks and he questioned whether some type of self-reinforcement was taking place. Tustin (1995) also incorporated visual signals of the changing tasks. Flannery and Horner (1994) although often cited as an example of an advance notice strategy, also included priming components in their predictability condition by modeling steps of upcoming tasks (noted by Schreibman et al. 2000). Many of the investigators posited the importance of increasing predictability that a change is going to occur and also what that change will be. While some studies have a potential confound between consistency and predictability, other studies (e.g., Flannery and Horner 1994; MacDuff et al. 1993) controlled for this by changing schedules and introducing new tasks over the course of data collection or in experimental phases subsequent to the initial treatment phase so that it cannot be argued that the person simply became accustomed to following the same daily routine. This factor led many authors to note the importance of predictability, perhaps over consistency. Studies generally had in common some form of advance exposure to the upcoming change or task. This might constitute pictorial exposure (e.g., Dettmer et al. 2000; MacDuff et al. 1993), a cue with materials related to the upcoming task (Tustin 1995), or video exposure (Buggey 2005; Schreibman et al. 2000). In most cases, advance exposure was simply in the form of some concrete or visual cue but in priming and modeling studies this sometimes involved actual practice of the activity/rehearsal in a different setting prior to demonstration in a target setting. Also important to note is that nearly all of the studies across categories have positive reinforcement for cooperation built into the procedures whether 
this is positive reinforcement for cooperation prior to the transition request (e.g., cooperation with high probability requests in behavioral momentum; in priming, cooperation with the priming procedure), reinforcement of transitioning from activity to activity, or both. In most studies it is not possible to evaluate the effectiveness of a component strategy in the absence of positive reinforcement, only in combination with it.

Another important difference across studies is whether or not functional assessments were incorporated into the design or relied upon in determining treatment. Some studies implemented antecedent interventions without evaluating potential function of problem behaviors (e.g., Buggey 2005) and still achieved positive results. Others incorporated functional assessments (e.g., Dooley et al. 2001; Flannery and Horner 1994; Fritz et al. 2004; Mace and Belfiore 1990). SterlingTurner and Jordan (2007) discussed previous research that demonstrated the utility of incorporating functional assessments of problem behaviors during transitions into the design and that treatment recommendations derived from functional assessments were beneficial. Waters et al. (2009) working with two 6-year-olds who displayed aggression during transitions conducted functional assessments that indicated problems were maintained by avoidance of non-preferred activities and access to preferred activities. Visual schedules alone were ineffective in reducing problem behaviors that occurred during transitions from preferred to non-preferred tasks; problem behaviors decreased when extinction and DRO were used.

Repetitive behaviors and refusal to transition can occur when repetitive, ritualistic behaviors allow ongoing access to a highly reinforcing tangible or sensory experience or may serve the function of avoiding a non-preferred activity (e.g., in Mace and Belfiore 1990) or can serve both functions (Waters et al. 2009). Some studies incorporating functional assessments have reported challenging behaviors that occurred during transitions (e.g., Dooley et al. 2001) were maintained by social attention. Other researchers have posited that restricted or repetitive responding was impacted by skills deficits and incorporated or emphasized skills building approaches (e.g., Stahmer 1995).

There may be differential effectiveness of strategies based on other factors. For an individual, does whether the person is being asked to transition to familiar or novel tasks impact difficulty with transition (as with Participant \#1 in Flannery and Horner 1994) or the effectiveness of an intervention? Are interventions more or less effective if the person is being asked to transition from a highly preferred to a non-preferred activity (reported in Fritz et al. 2004 prior to treatment; Cihak (2011) demonstrated efficacy in promoting transitions from more to less preferred activities). Well-controlled studies that further evaluate the effect of interventions on transitions among tasks that are equally appetitive or equally aversive, looking at impact on delays in transitions and on problem behaviors, would add to the literature. Boyd et al. (2012) matched interventions with problem topography and discussed strategies paired with groupings of "lower order" behaviors (e.g., stereotyped movements, repetitive manipulation of objects, and repetitive forms of self-injury) vs. "higher order" behaviors (e.g., compulsions, rituals and routines, insistence on sameness, and circumscribed interests). Are there different clinical considerations whether or not the person has deficits relative to skills required to succeed in the next activity?

Reviewing the collection of studies taken together may lead to some general considerations. Interventions are typically chosen in the context of assessment methodologies and based on accompanying hypotheses about the nature of the problem. A comprehensive assessment of transition difficulties might include thorough assessment of the topographies of behavioral inflexibility (as discussed in Green et al. 2006) as well as functional assessment of transition-related problems. Additional assessment which may yield helpful information might include assessment of patterns and circumstances associated with problems including whether or not problems are impacted by transitions to novel or familiar tasks and/or transitions to non-preferred tasks, whether or not problems occur in the context of the person displaying severely perseverative or stereotypical behavior, and whether there appear to be skills deficits contributing to restricted responding or skill deficits which might impair performance in the upcoming task. In practice, different interventions are likely to be selected by clinicians based on these types of hypotheses. If a principle hypothesis is that the need for predictability in autism is a primary contributing factor, advance notice strategies, visual schedules, or priming may be featured in interventions. If being stuck in repetitive patterns or perseverative responding is hypothesized to be a relevant contributing factor, altered timing, transfer stimuli, or behavioral momentum may be among selected strategies. Where operant factors emerge as relevant through functional assessment, reinforcement, replacement behavior training, and extinction procedures are likely to be incorporated. Where additional skills deficits appear to be relevant, priming and/or modeling may be featured components of treatment. While this may describe how selection often takes place in clinical practice, future research on matching intervention to assessment results and whether this type of matching results in more effective treatment is needed.

Also with regard to future research, there are a number of behavioral strategies that have been applied to improving problems related to other forms of restrictive, repetitive behaviors in persons with an ASD that have not been studied in relation to supporting transitions. For example, differential reinforcement of variability and lag reinforcement schedules, in which reinforcement is contingent upon the person displaying behavior that is novel or different from previous responses (Miller and Neuringer 2000; Lee et al. 2007), have been used with persons with autism to increase diverse play 
behaviors and to decrease sameness behaviors such as time engaged in restricted behaviors and perseveration with objects (Boyd et al. 2011). Also, there is a growing body of literature on the use of social scripts to increase social initiations, expand verbal repertoires, and ease participation into conversation (Ganz et al. 2012; Lee and Sturmey 2014; Stevenson et al. 2000). However, the authors were unable to find studies where social scripts were used specifically to facilitate transitioning from one topic to another. In addition, offering more choice within tasks has been used to improve participation in work (Watanabe and Sturmey 2003) and educational activities (Moes 1998). However, with the possible exception of Koegel et al. (2006b) in which choice regarding order of assignments and material selection was used to assist 8-year-old twins with an ASD with transitioning from leisure time into homework, the study of specific applications of choice to facilitate transitions was not identified as part of this review. It remains to be evaluated whether differential reinforcement of variability, social scripts, and increasing choice could be usefully employed to support transitions. In exploring novel approaches, there may be merit in future research in applying to transitions some strategies that research suggests have been beneficial in facilitating change and decreasing other types of restricted responding.

Another area for future research may relate to the further discussion and study of potential applicability of interventions for treating anxiety to transition difficulties. MacNeil et al. (2009)) reviewed literature on the high prevalence of anxiety symptoms in ASDs. Lidstone et al. (2014) exploring relationships between different restricted/repetitive behaviors, sensory reactivity, and anxiety proposed a connection in some cases between insistence on sameness and anxiety. They cited other researchers who have proposed a role of repetitive/restricted behaviors in attempting to correct imbalances in unpleasant sensory over- or under-arousal and insistence on sameness rituals potentially serving as a buffer for anxiety. Without assuming this is always the case, it is possible transition avoidance is negatively reinforced in some persons by anxiety reduction, a phenomenon that some individuals with an ASD and good verbal skills directly report. Effective treatments for anxiety symptoms and avoidance behavior in persons with developmental disabilities have been described in the literature for decades. Some desensitization and participant modeling approaches (Matson 1981; Love et al. 1990) and cognitive-behavioral approaches (Van Steensel et al. 2014) bear topographical similarities with transition-related treatments (which can incorporate variations of in-advance exposure, hierarchical exposure, pictorial or video exposure, modeling, participant modeling, neutralizing routines, utilizing Pavlovian counterconditioning approaches). Further study may be warranted.

One limitation of the current review paper is that it focuses on assisting individuals to tolerate changes and transitions that occur through the day. This article does not explore current supports surrounding assisting persons with sameness issues in adjusting to major life transitions. For example, Forest et al. (2004) describes a step-by-step process to assist young children with autism to transition from pre-school to kindergarten. The methodical approach incorporates a series of visits and gradual exposure experiences to the new setting and teachers and planning that begins a full year in advance to optimize readiness. These interventions also bear some resemblance to desensitization therapy. There is a growing body of literature discussing supports for persons with Autism Spectrum Disorders entering universities (Dolyniuk et al. 2002; Glennon 2001; Shields et al. 2008) as well as other transition supports for adulthood (Floyd et al. 2009; King et al. 2005). Helping individuals to prepare for major life transitions to avoid predictable crises has been advocated by prominent researchers in the field (Aman et al. 2004; Levitas and Gilson 2001; Rush and Frances 2000). These topics were outside the scope of this current review.

Acknowledgments The authors would like to thank Donna Francis, Developmental Disabilities Services Director of the Metropolitan Human Service District, for her assistance at the initiation of this review and her support of this project.

\section{References}

Aman, M. G., Crismon, M. L., Frances, A., King, B., \& Rojahn, J. (2004). Treatment of psychiatric and behavioral problems in individuals with mental retardation: An update of the expert consensus guidelines. Englewood: Postgraduate Institute for Medicine.

American Psychiatric Association. (2000). Diagnostic and statistical manual of mental disorders (4th ed., text revision). Washington, DC: Author.

American Psychiatric Association. (2013). Diagnostic and statistical manual of mental disorders (5th ed.). Washington: Author.

Ardoin, S. P., Martens, B. K., \& Wolfe, L. A. (1999). Using highprobability instruction sequences with fading to increase student compliance during transitions. Journal of Applied Behavior Analysis, 32, 339-351.

Banda, D. R., \& Grimmett, E. (2008). Enhancing social and transition behaviors of persons with autism through activity schedules: a review. Education and Training in Developmental Disabilities, 43, 324-333.

Banda, D. R., Grimmett, E., \& Hart, S. L. (2009). Helping students with autism spectrum disorders in general education classrooms manage transition issues. Teaching Exceptional Children, 41(4), 16-21.

Boyd, B. A., McDonough, S. G., Rupp, B., Khan, F., \& Bodfish, J. W. (2011). Effects of a family-implemented treatment on the repetitive behaviors of children with autism. Journal of Autism and Developmental Disorders, 41, 1330-1341.

Boyd, B. A., McDonough, S. G., \& Bodfish, J. W. (2012). Evidencebased behavioral interventions for repetitive behaviors in autism. Journal of Autism and Developmental Disorders, 42, 1236-1248.

Bryan, L. C., \& Gast, D. L. (2000). Teaching on-task and on-schedule behaviors to high-functioning children with autism via picture activity schedules. Journal of Autism and Developmental Disorders, 30(6), 553-567. 
Buggey, T. (2005). Video self-modeling applications with students with autism spectrum disorders in a small private school setting. Focus on Autism and Other Developmental Disabilities, 20, 52-63.

Cihak, D. F. (2011). Comparing pictorial and video modeling activity schedules during transitions for students with autism spectrum disorders. Research in Autism Spectrum Disorders, 5, 433-441.

Cohen, H., Amerine-Dickens, M., \& Smith, T. (2006). Early intensive behavioral treatment: replication of the UCLA model in a community setting. Developmental and Behavioral Pediatrics, 27, S145S155.

D’Elia, L., Valeri, G., Sonnino, F., Fontana, I., Mammone, A., \& Vicari, S. (2014). A longitudinal study of the TEACCH program in different settings: the potential benefits of low intensity intervention in preschool children with autism spectrum disorders. Journal of Autism and Developmental Disorders, 44, 615-626.

Dettmer, S., Simpson, R. L., Myles, B. S., \& Ganz, J. B. (2000). The use of visual supports to facilitate transitions of students with autism. Focus on Autism and Other Developmental Disabilities, 15(3), 163169

Dolyniuk, C. A., Kamens, M. W., Corman, H., DiNardo, P. O., Totaro, R. M., \& Rockoff, J. C. (2002). Students with developmental disabilities go to college: description of a collaborative transition project: on a regular college campus. Focus on Autism and Other Developmental Disabilities, 17(4), 236-241.

Dooley, P., Wilczenski, F. L., \& Torem, C. (2001). Using an activity schedule to smooth school transitions. Journal of Positive Behavior Interventions, 3, 57-61.

Eikseth, S. (2009). Outcome of comprehensive psycho-educational interventions for young children with autism. Research in Developmental Disabilities, 30, 158-178.

Evans, D. W., Leckman, J. F., Carter, A., Reznick, J. S., Henshaw, D., King, R. A., et al. (1997). Ritual, habit and perfectionism: the prevalence and development of compulsive-like behavior in normal young children. Child Development, 68(1), 58-68.

Flannery, K. B., \& Horner, R. H. (1994). The relationship between predictability and problem behavior for students with severe disabilities. Journal of Behavioral Education, 4, 157-176.

Floyd, F. J., Costigan, C. L., \& Piazz, V. E. (2009). The transition to adulthood for individuals with intellectual disability. International Review of Research in Mental Retardation, 37, 31-59.

Forest, E. J., Horner, R. H., Lewis-Palmer, T., \& Todd, A. W. (2004). Transitions for young children with autism. Journal of Positive Behavior Interventions, 6(2), 103-112.

Fredeen, R. M., \& Koegel, R. L. (2006). The pivotal role of initiations in habilitation. In R. L. Koegel \& L. K. Koegel (Eds.), Pivotal response treatments for autism: communication, social, and academic development. Baltimore: Paul H. Brooks Publishing Co.

Fritz, J. N., DeLeon, I. G., \& Lazarchich, W. N. (2004). Separating the influence of escape and access to preferred activities on problem behaviors occurring in instructional contexts. Behavioral Interventions, 19, 159-171.

Ganz, J. B., Heath, A. K., Lund, E. M., Camargo, S. P. H., Rispoli, M. J., Boles, M., \& Plaisance, L. (2012). Effects of peer-mediated implementation of visual scripts in middle school. Behavior Modification, 36(3), 378-398.

Gentry, T., Lau, S., Molinelli, A., Fallen, A., \& Kriner, R. (2012). The apple ipod touch as a vocational support aid for adults with autism: three case studies. Journal of Vocational Rehabilitation, 37(2), 7585.

Glennon, T. J. (2001). The stress of the university experience for students with Asperger syndrome. Work, 17, 183-190.

Goldstein, H. (2002). Communication intervention for children with autism: a review of treatment efficacy. Journal of Autism and Developmental Disorders, 32, 373-396.

Green, V. A., Sigafoos, J., Pituch, K. A., Itchon, J., O’Reilly, M., \& Lancioni, G. E. (2006). Assessing behavioral flexibility in individuals with developmental disabilities. Focus on Autism and Other Developmental Disabilities, 21(4), 230-236.

Hodgson, L. A. (1995). Visual strategies for improving communication system training manual. Troy: Quirk Roberts.

Howard, J. S., Sparkmann, C. R., Cohen, H. G., Green, G., \& Stanislaw, H. (2005). A comparison of intensive behavior analytic and eclectic treatments for young children with autism. Research in Developmental Disabilities, 26, 359-383.

Howlin, P., \& Rutter, M. (1987). Treatment of autistic children. Great Britain: Wiley.

Huang, A. X., \& Wheeler, J. J. (2006). Effective interventions for individuals with high-functional autism. International Journal of Special Education, 21, 165-175.

Jones, E. A., Carr, E. G., \& Feeley, K. M. (2006). Multiple effects of joint attention for children with autism. Behavior Modification, 30, 782 834.

Kanner, L. (1943). Autistic disturbances of affective contact. The Nervous Child, 2, 217-250.

King, G. A., Baldwin, P. J., Currie, M., \& Evans, J. (2005). Planning successful transitions from school to adult roles for youth with disabilities. Children's Health Care, 34(3), 195-216.

Koegel, R. L., \& Covert, A. (1972). The relationship to self-stimulation to learning in autistic children. Journal of Applied Behavior Analysis, $5,381-387$.

Koegel, R. L., \& Koegel, L. K. (2006). Pivotal response treatments for autism: communication, social, and academic development. Baltimore: Paul H. Brooks Publishing Co.

Koegel, R. L., Koegel, L. K., \& McNerney, E. K. (2001). Pivotal areas in intervention for autism. Journal of Clinical Child Psychology, 30, $19-32$.

Koegel, R. L., Talebi, J. L., \& Koegel, L. K. (2006a). Reducing ritualistic behaviors and broadening children's interests. In R. L. Koegel \& L. K. Koegel (Eds.), Pivotal response treatments for autism: communication, social, and academic development. Baltimore: Paul $\mathrm{H}$. Brooks Publishing Co.

Koegel, R. L., Tran, Q., Mossman, A., \& Koegel, L. K. (2006b). Incorporating motivational procedures to improve homework performance. In R. L. Koegel \& L. K. Koegel (Eds.), Pivotal response treatments for autism: communication, social, and academic development. Baltimore: Paul H. Brooks Publishing Co.

Koyama, T., \& Wang, H. (2011). Use of activity schedule to promote independent performance of individuals with autism and other intellectual disabilities: a review. Research in Developmental Disabilities, 32, 2235-2242.

Lee, R., \& Sturmey, P. (2014). The effects of script-fading and a lag1 schedule on varied social responding in children and autism. Research in Autism Spectrum Disorders, 8, 440-448.

Lee, R., Sturmey, P., \& Fields, L. (2007). Schedule-induced and operant mechanisms that influence response variability: a review and implications for future investigations. Psychological Record, 57(3), 429455.

Lequia, J., Machalicek, W., \& Rispoli, M. J. (2012). Efficacy of activity schedules on challenging behavior exhibited in children with autism spectrum disorders: a systematic review. Research in Autism Spectrum Disorders, 6, 480-492.

Levitas, A., \& Gilson, S. F. (2001). Predictable crises in the lives of persons with mental retardation. Mental Health Aspects of Developmental Disabilities, 4(3), 89-100.

Lidstone, J., Uljarevic, M., Sullivan, J., Rodgers, J., McConachie, H., Freeston, M., ... Leekam, S. (2014). Relations among restricted and repetitive behaviors, anxiety and sensory features in children with autism spectrum disorders. Research in Autism Spectrum Disorders, 8, 82-92.

Lord, C., Rutter, M., \& Le Couteur, A. (1994). Autism diagnostic interview-revised: a revised version of a diagnostic interview for 
caregivers of individuals with possible pervasive developmental disorders. Journal of Autism and Developmental Disorders, 23, 659685.

Lord, C., Risi, S., Lambrecht, L., Cook, E. H., Leventhal, B. L., DiLavore, P. C., ...Rutter, M. (2000). The autism diagnostic observation schedule - generic: a standard measure of social and communication deficits associated with the spectrum of autism. Journal of Autism and Developmental Disorders, 30, 205-223.

Love, S. R., Matson, J. L., \& West, D. (1990). Mothers as effective therapists for autistic children's phobias. Journal of Applied Behavior Analysis, 23, 379-385.

MacDuff, G. S., Krantz, P. J., \& McClanahan, L. E. (1993). Teaching children with autism to use photographic activity schedules: maintenance and generalization of complex response chains. Journal of Applied Behavior Analysis, 26, 89-97.

Mace, F. C., \& Belfiore, P. (1990). Behavioral momentum in the treatment of escape-motivated stereotypy. Journal of Applied Behavior Analysis, 23, 507-514.

Mace, F. C., Hock, M. L., Lalli, J. S., West, B. J., Belfiore, P., Pinter, E., \& Brown, D. K. (1988). Behavioral momentum in the treatment of noncompliance. Journal of Applied Behavior Analysis, 21, 123141.

MacNeil, B. M., Lopes, V. A., \& Minnes, P. M. (2009). Anxiety in children and adolescents with autism spectrum disorders. Research in Autism Spectrum Disorders, 3, 1-21.

Matson, J. L. (1981). A controlled group outcome study of phobias in mentally retarded adults. Behavior Research and Therapy, 19, 101107.

Matson, J. L., \& Minshawi, N. F. (2006). Early intervention for autism spectrum disorders: a critical analysis. Oxford: Elsevier Science Inc.

Matson, J. L., \& Nebel-Schwalm, M. (2006). Assessing challenging behaviors in children with autism spectrum disorders: a review. Research in Developmental Disabilities, 28, 109-118.

Matson, J. L., \& Smith, K. R. M. (2008). Current status of intensive behavioral interventions for young children with autism and PDDNOS. Research in Autism Spectrum Disorders, 2, 60-74.

Matson, J. L., Dempsey, T., \& Fodstad, J. C. (2009a). Stereotypies and repetitive/restrictive behaviors in infants with autism and pervasive developmental disorder. Developmental Neurorehabilitation, 12, $122-127$.

Matson, J. L., Mahan, S., \& LoVullo, S. V. (2009b). Parent training: a review of methods for children with developmental disabilities. Research in Developmental Disabilities, 30, 961-968.

Matson, J. L., Wilkins, J., Sevin, J. A., Knight, C., Boisjoli, J. A., \& Sharp, B. (2009c). Reliability and item content of the Baby and Infant Screen for Children with aUtIsm Traits (BISCUIT): parts 13. Research in Autism Spectrum Disorders, 3, 336-344.

McClannahan, I. F., \& Krantz, P. I. (1999). Activity schedules for children with autism: teaching independent behavior. Bethesda: Woodbine.

Mechling, L. C., \& Savidge, E. J. (2010). Using a personal digital assistant to increase completion of novel tasks and independent transitioning by students with autism spectrum disorder. Journal of Autism and Developmental Disorders, 41, 687-704.

Mesibov, G. B., \& Shea, V. (2010). The TEACCH program in the era of evidence-based practice. Journal of Autism and Developmental Disorders, 40, 570-579.

Mesibov, G. B., Shea, V., \& Schopler, E. (Eds.). (2005). The TEACCH approach to autism spectrum disorders. New York: Springer.

Mialaret, G. J. (1996). Dancing with dragons: an entire family's insights into a disability. Arlington: Future Horizons Inc.

Miller, N., \& Neuringer, A. (2000). Reinforcing variability in adolescents with autism. Journal of Applied Behavior Analysis, 33, 151-165.

Miltenberger, R. G. (2006). Antecedent interventions for challenging behaviors maintained by escape from instructional activities. In J. K. Luiselli (Ed.), Antecedent assessment \& intervention: supporting children and adults with developmental disabilities in community settings. Baltimore: Paul H. Brookes Publishing Co.

Moes, D. R. (1998). Integrating choice-making opportunities within teacher-assigned academic tasks to facilitate the performance of children with autism. Journal of the Association for Persons with Severe Handicaps, 23, 319-328.

Nevin, J. A., Mandell, C., \& Atak, J. R. (1983). The analysis of behavioral momentum. Journal of the Experimental Analysis of Behavior, $39,49-59$.

Odom, S. L., Boyd, B. A., Hall, J. J., \& Hume, K. (2010). Evaluation of comprehensive treatment models for individuals with autism spectrum disorders. Journal of Autism and Developmental Disorders, 40, 425-436.

Palmen, A., Didden, R., \& Verhoeven, L. (2012). A personal digital assistant for improving independent trasitioning in adolescents with high-functioning autism spectrum disorders. Developmental Neurorehabilitation, 15(6), 401-413.

Panerai, S., Ferrante, L., \& Zingale, M. (2002). Benefits of the treatment and education of autistic and communication handicapped children (TEACCH) programme as compared with a non-specific approach. Journal of Intellectual Disability Research, 46(4), 318-327.

Panerai, S., Zingale, M., Trubia, G., Finocchiaro, M., Zuccarello, R., Ferri, R., \& Elia, M. (2009). Special education versus inclusive education: the role of the TEACCH program. Journal of Autism and Developmental Disorders, 39, 874-882.

Prior, M., \& MacMillan, M. B. (1973). Maintenance of sameness in children with Kanner's syndrome. Journal of Autism and Childhood Schizophrenia, 3(2), 154-167.

Probst, P., \& Glen, I. (2011). TEACCH-based interventions for families with children with autism spectrum disorders: outcomes of a parent group training study and a home-based child-parent training single case study. Life Span and Disability, 14(2), 111-138.

Probst, P., \& Leppert, T. (2008). Brief report: outcomes of a teacher training program for autism spectrum disorders. Journal of Autism and Developmental Disorders, 38, 1791-1796.

Probst, P., Jung, F., Micheel, J., \& Glen, I. (2010). Tertiary-preventive interventions for autism spectrum disorders (ASD) in children and adults: An evaluative synthesis of two TEACCH based outcome studies. Life Span and Disability, 13(12), 129-167.

Reese, R. M., Richman, D. M., Zarcone, J., \& Zarcone, T. (2003). Individualizing functional assessment for children with autism: the contribution of perseverative behavior and sensory disturbances to disruptive behaviors. Focus on Autism and Other Developmental Disabilities, 18, 89-94.

Rojahn, J., Matson, J. L., Mahan, S., Fodstad, J. C., Knight, C., Sevin, J., $\&$ Sharp, B. (2009). Cutoffs, norms, and patterns of problem behaviors in children with an ASD on the Baby and Infant Screen for Children with aUtIsm Traits (BISCUIT-Part 3). Research in Autism Spectrum Disorders, 23, 989-998.

Rush, A. J., \& Frances, A. (2000). Expert consensus guideline series: treatment of psychiatric and behavioral problems in mental retardation. American Journal on Mental Retardation, 105(3), 159-228.

Rutter, M. (1971). The description and classification of infantile autism. In Churchill, D. W., Alpern, G. D., \& DeMeyer, M. K. (Eds.), Infantile autism. Springfield, Ill.: CC Thomas.

Rutter, M. (1978). Diagnosis and definition. In M. Rutter (Ed.), Autism: a reappraisal of concepts and treatment. New York: Plenum Press.

Schopler, E. (1989). Principles for directing both educational treatment and research. In C. Gillberg (Ed.), Diagnosis and treatment of autism. New York: Plenum Press.

Schopler, E. (1994). A statewide program for the treatment and education of autistic and related communication handicapped children (TEACCH). Psychosis and Pervasive Disorders, 3, 91-103.

Schopler, E., Mesibov, G. B., \& Hearsey, K. (1995). Structured teaching in the TEACCH system. In E. Schopler \& G. Mesibov (Eds.), Learning and cognition in autism. New York: Plenum Press. 
Schopler, E., Van Bourgondien, M. E., Willman, G. J., \& Love, S. R. (2010). Childhood autism rating scale (2nd ed.). Western Psychological Services.

Schreibman, L., Whalen, C., \& Stahmer, A. C. (2000). The use of video priming to reduce disruptive transition behavior in children with autism. Journal of Positive Behavior Interventions, 2, 3-11.

Sevin, J. A., Bower-Stephens, C., Hamilton, M. H., \& Ford, A. (2001). Integrating behavioral and pharmacological interventions in treating clients with psychiatric disorders and mental retardation. Research in Developmental Disabilities, 22, 463-485.

Sherer, M. R., \& Schreibman, L. (2005). Individual behavioral profiles and predictors of treatment effectiveness for children with autism. Journal of Consulting and Clinical Psychology, 73, 525-538.

Shields, B. A., Saladino, A., Proctor-Szilagyi, A. M. F., \& Doueck, H. J. (2008). An integrative model for developing transition-based dormitory experiences for individuals with developmental disabilities on college campuses. Journal of Transformative Education, 6, 8294.

Stahmer, A. C. (1995). Teaching symbolic play skills to children with autism using pivotal response training. Journal of Autism and Developmental Disabilities, 25, 123-141.

Sterling-Turner, H. E., \& Jordan, S. S. (2007). Interventions addressing transition difficulties for individuals with autism. Psychology in the Schools, 44(7), 681-690.

Stevenson, C. L., Krantz, P. J., \& McClannahan, L. E. (2000). Social interaction skills for children with autism: a script-fading procedure for nonreaders. Behavioral Interventions, 15(1), 1-20.

Taber-Doughtry, T., Miller, B., Shurr, J., \& Wiles, B. (2013). Portable and accessible video modeling: teaching a series of novel skills within school and community settings. Education and Training in Autism and Developmental Disabilities, 48, 147-163.

Tustin, R. D. (1995). The effects of advance notice of activity transitions on stereotypic behavior. Journal of Applied Behavior Analysis, 28, 91-92.

Van Steensel, F. J. A., Dirksen, C. D., \& Bogels, S. M. (2014). Costeffectiveness of cognitive-behavioral therapy versus treatment as usual for anxiety disorders in children with autism spectrum disorder. Research in Autism Spectrum Disorders, 8, 127-137.

Wahlberg, T., \& Jordan, S. (2001). A case study in the dynamics of autism. In T. Wahlberg, F. Obiakor, S. Burkhardt, \& A. F. Rotari (Eds.), Autistic spectrum disorder: Educational and clinical interventions. Advances in special education (Vol. 14, pp. 53-65). Oxford: Elsevier Science.

Watanabe, M., \& Sturmey, P. (2003). The effect of choice-making opportunities during activity schedules on task engagement of adults with autism. Journal of Autism and Developmental Disorders, 33(5), $535-538$

Waters, M. B., Lerman, D. C., \& Hovanetz, A. N. (2009). Separate and combined effects of visual schedules and extinction plus differential reinforcement on problem behavior occasioned by transitions. Journal of Applied Behavior Analysis, 42(2), 309-313.

Welterlin, A., Turner-Brown, L. M., Harris, S., Mesibov, G., \& Delmolino, L. (2012). The home TEACCHing program for toddlers with autism. Journal of Autism and Developmental Disorders, 42, $1827-1835$.

Zanolli, K., Daggett, J., \& Adams, T. (1996). Teaching preschool age autistic children to make spontaneous initiations to peers using priming. Journal of Autism and Developmental Disorders, 26, 407-422. 